(6)

\section{OPEN ACCESS}

Economics of Tobacco Control Project, School of Economics, University of Cape Town, Cape Town, South Africa

Correspondence to Nicole Vellios, Economics of Tobacco Control Project, School of Economics, University of Cape Town, Cape Town, South Africa; nicole.vellios@uct.ac.za

Received 17 October 2018 Revised 25 January 2019 Accepted 28 January 2019

Check for updates

(c) Author(s) (or their employer(s)) 2019. Re-use permitted under CC BY. Published by BMJ.

To cite: Vellios $\mathrm{N}$, van Walbeek C, Ross $\mathrm{H}$.

Tob Contro/ Epub ahead of print: [please include Day

Month Year]. doi:10.1136/

tobaccocontrol-2018-054798

\title{
Illicit cigarette trade in South Africa: 2002-2017
}

\author{
Nicole Vellios, ${ }^{\circledR}$ Corné van Walbeek, ${ }^{\oplus}$ Hana Ross ${ }^{\oplus}$
}

\section{ABSTRACT \\ Background Increasing cigarette excise taxes is widely recognised as the most effective measure to reduce the demand for cigarettes. The presence of illicit trade undermines the effectiveness of tax increases as both a public health and a fiscal measure, because it introduces cheaper alternatives to legal, full-priced cigarettes.}

Objective To assess trends in the size of the illicit cigarette market in South Africa from 2002 to 2017 using gap analysis.

Methods Tax-paid cigarette sales are compared with consumption estimates from two nationally representative surveys: the All Media and Products Survey and the National Income Dynamics Study. We explore the size of the illicit cigarette market and its changes over the period 2002-2017.

Results Since 2009, illicit trade has increased sharply. We estimate that illicit trade is between 30\% and 35\% of the total market in 2017. The acceleration in the growth of the illicit market since 2015 corresponds with a turbulent time at the South African Revenue Service, when many of the enforcement functions were greatly reduced.

Conclusions The current levels of illicit trade are extremely high and need to be addressed urgently by implementing effective control mechanisms such as a track and trace system to monitor the production, taxation, and sale of cigarettes.

\section{INTRODUCTION}

South Africa was one of the first middle-income countries to use excise tax increases as a tobacco control tool. In 1994, the government announced that it aimed to set the excise tax, which is levied as a specific tax, such that the total tax burden would equal $50 \% .^{1}$ The total tax includes excise tax plus value-added tax (VAT), expressed as a percentage of the retail price of the most popular brand. The $50 \%$ target was achieved in $1997 .{ }^{1}$ Since then, the only change occurred in 2004, when the government increased the total tax burden target to $52 \%$ of the retail price. ${ }^{2}$

Although government sets the tax rate, the tobacco industry decides on the retail price. As a result, the tobacco industry has effectively controlled the amount of the excise tax paid by consumers for many years. Between 1995 and 2017, the real (inflation-adjusted) excise tax increased at an average rate of $7.2 \%$ per year. The largest tax growth occurred between 1995 and 2011 when the real excise tax increased at an average rate of 9.7\% per year but it slowed markedly to $1 \%$ per year between 2011 and 2017. ${ }^{3}$ The increase in the 1995-2011 period was driven largely by the tobacco industry's pricing strategy. Following this period, the tobacco industry revised their pricing strategy as a result of newcomers (who offered low-priced cigarettes) entering the market. ${ }^{1}$

In addition to very modest excise increases in recent years, South Africa has to date (June 2019) failed to adopt the best international practices in tax administration. It only uses a simple and barely visible imprint of a diamond-shaped excise stamp to mark cigarette packs destined for the domestic market. The tax authority has little control over the use of the diamond stamp impression, which is easy to counterfeit and impossible to verify. There is no link between tax payment and the stamp.

Without an effective excise tax monitoring system, tax evasion can erode the effectiveness of tax increases. ${ }^{4}$ In addition, this effectiveness can be undermined by tax avoidance, for example, when consumers buy cigarettes from lower tax jurisdictions in the allowed quantities. It is unlikely that there is much tax avoidance in South Africa due to cross-border shopping, since cigarette prices in neighbouring countries are either similar or higher, as a result of a common excise tax in the Southern African Customs Union (South Africa, Botswana, Lesotho, Namibia and Swaziland). ${ }^{5}$

Other forms of tax avoidance in South Africa are minimal. There are no duty-free shops, aside from those at airports. As far as we are aware, internet purchases of cigarettes are also not prominent in South Africa. Existing legislation does not allow tobacco manufacturers to engage in tax avoidance by changing their products' characterisitics and prices with the objective of reducing their tax liability. The same amount of excise tax is levied per pack of 20 cigarettes, regardless of the product's features.

Tax evasion, on the other hand, is a significant issue, which is acknowledged by both independent researchers and the tobacco industry. ${ }^{6}$ Historically, the extent of the problem was controversial as the estimates provided by the tobacco industry were typically higher than estimates by independent researchers.

The Tobacco Institute of Southern Africa (TISA), a body representing the interests of the multinationals, estimated the illicit cigarette market share at about $20 \%$ in the period of 2006 to early 2011, with a sharp increase towards the end of 2011 $(25 \%)$ and in 2012 (30\%). ${ }^{8}$ TISA's 2016 estimate puts the illicit market share back at $23 \%$. $^{7}$ In statements to the media, TISA emphasises revenue losses due to the large illicit market.

Needless to say, TISA's estimates must be interpreted with caution given that TISA has an incentive to exaggerate the threat of the illicit market. In addition, TISA has retrospectively adjusted illicit trade estimates to fit the narrative about the growing danger of illicit trade. The methodology of how these estimates were calculated is 
not shared publicly. For example, in a 2012 presentation to National Treasury, TISA claimed that the 2008 illicit market share was $7.9 \%$, in sharp contrast with its earlier claim (made in 2008 and 2009) that the illicit market share was 20\% in that year. ${ }^{8}$ A 2018 article that systematically analyses global tobacco industry data on illicit trade concludes that these data are unreliable. ${ }^{9}$

Euromonitor, a market research firm, reports an illicit market share in South Africa that is broadly consistent with TISA estimates. However, the credibility of Euromonitor's estimates is questionable since, like those of TISA, they exhibit striking inconsistencies across different report editions. ${ }^{10}$

Previous studies by independent academics disagree with industry estimates. Blecher estimated the size of the illicit market to be between $9.4 \%-11.5 \%$ and $7 \%-11.2 \%$ of the total market in 2000 and 2007, respectively. ${ }^{11}$ Van Walbeek compared the change in legal cigarette sales with the predicted change in total consumption (legal and illicit) to quantify changes in the illicit cigarette market from 1995 to $2012 .{ }^{8}$ He found that there was no evidence of a substantial change in the share of the illicit market prior to 2009 , but that there was a substantial spike in 2010.

In a 2014 presentation, the South African Revenue Service (SARS) reported that $29 \%$ of the total market consisted of illegal cigarettes. ${ }^{12}$ The methodology is not described in the presentation. We were unable to find any more recent estimates from SARS.

The latest estimate of the size of the illicit cigarette market comes from the tobacco industry, who commissioned market-research firm Ipsos to conduct the study. Ipsos audited 2058 independent retail outlets in South Africa ${ }^{13}$ and found that $27 \%$ of the cigarette market in South Africa is illicit. ${ }^{14}$ Ipsos defined illicit cigarettes as those with a price below R17.85 per pack, which is the excise tax and VAT applicable in 2018 (about $\$ 1.30$ in October 2018). ${ }^{13}$ Ipsos reports that illicit cigarettes were sold in almost three out of four of the outlets audited and found that smaller local manufacturers were the producers of the illicit brands. ${ }^{13}$ This is not surprising given that TISA is an industry group for the multinationals, which are in competition with the local tobacco industry. ${ }^{15}$ TISA has used the results of the Ipsos study to run a comprehensive \#TakeBackTheTax campaign in which they call on the government to curb illicit trade.

Many cigarettes in South Africa, including those that are illegal, are sold as single sticks. Historical corporate documents indicate that the sale of single cigarettes, which makes smoking affordable and accessible for the poor and young, underpins industry expansion in Africa. ${ }^{16}$

The South African market is dominated by British American Tobacco (BAT) who, in 2016, held about 74\% of the market share, followed by Japan Tobacco International (9\%) and Philip Morris (8\%). ${ }^{17}$ The market share of the multinationals has decreased in the past few years as a result of competitive local manufacturers. For example, BAT's market share decreased from $81 \%$ in 2012 to $74 \%$ in 2016 while Gold Leaf Tobacco, a prominent local company, increased its market share from 3\% in 2012 to $6 \%$ in $2016 .^{17}$

The aim of this study is to provide independent estimates of illicit trade in South Africa from 2002 to 2017. These estimates are compared with existing independent studies and those produced by the tobacco industry. In the Discussion section, we also explore how the management crisis at SARS impacted the illicit trade in tobacco products.

\section{METHODS AND DATA}

Gap analysis is one of several methods used to measure the size of the illicit cigarette market. ${ }^{18}$ It is based on a comparison of consumption estimates (from survey data) with legitimate sales (as declared to the excise tax authority). The gap between these two measures is an indication of the size of the illicit market, while taking into account under-reporting. Gap analysis is the primary method employed by Her Majesty's Revenue \& Customs (HMRC) in the UK, ${ }^{19}$ but has been conducted in other countries such as Argentina, Brazil, Chile, Colombia, Peru; ${ }^{20}$ Canada; ${ }^{21} 22$ the USA $;^{23}$ Vietnam; ${ }^{24}$ and South Africa. ${ }^{11}$

One of the weaknesses of the gap analysis method is the issue of under-reported cigarette consumption in survey data. It is widely accepted that people under-report socially undesirable behaviours. ${ }^{25-27}$ In addition, consumption may also be under-reported because of recall error, where participants do not correctly remember how many cigarettes they consumed. ${ }^{18}$ Survey respondents also tend to report their consumption in round numbers, for example, at 5, 10 and 20 cigarettes per day.

In his study of five South American countries, Paraje does not make any assumptions about the level of under-reporting, but assumes that under-reporting is consistent over time. ${ }^{20}$ This allows him to compare trends in illicit trade over time, but not to assess the size of the illicit cigarette market. Guindon et al present trends in the illicit trade market in Quebec, Ontario and Canada for 1999-2013. ${ }^{22}$ The authors also present estimates for illicit trade in Ontario using under-reporting levels of 35\% and $40 \%$ for years they have information on under-reporting (2007, 2009-2011). These levels were chosen as self-reported consumption represented about $65 \%$ and $60 \%$ of tax-paid consumption, depending on the data set used. ${ }^{22}$

HMRC uses an 'uplift factor' to account for under-reporting. To quantify the under-reporting bias, the uplift factor is calculated by dividing total legitimate (ie, tax-paid) consumption by total self-reported consumption in a year when illicit trade is believed to be negligibly small (in which case under-reporting is the only unknown variable). This factor is applied to self-reported consumption to upscale the estimates in subsequent years. ${ }^{19}$ HMRC calculates both the size of and the trends in the illicit cigarette market in the UK. ${ }^{19}$ Nguyen et al employ three levels of under-reporting $(10 \%, 20 \%$ and $30 \%)$ to conduct a sensitivity analysis for estimates generated using data from Vietnam, ${ }^{24}$ while Blecher, in his study of the South African market, assumes $5 \%$ and $10 \%$ levels of under-reporting. ${ }^{11}$

Szklo et $a l^{28}$ estimated under-reporting in Brazil using a previous study's ${ }^{29}$ estimate of illegal consumption. Iglesias et $a l^{29}$ estimate illicit trade in 2013 in Brazil by using a threshold price to distinguish licit from illicit cigarettes. Szklo et al use this estimate, together with data on self-reported consumption and legal sales, to estimate under-reporting (which is assumed to be constant).

We use data from two nationally representative surveys to estimate the total size of South African cigarette market: the All Media and Products Survey (AMPS, 2002-2014) ${ }^{30} 31$ and the National Income Dynamics Study (NIDS, 2008, 2010, 2012, 2015, 2017)..$^{32-36}$

AMPS is a cross-sectional survey that considers the use of products (eg, cigarettes, alcohol and energy drinks), traditional media (eg, newspapers) and services (eg, banking). It was conducted annually since 1993, but was discontinued in 2015. It uses a multistage, area-stratified probability sample and provides sample weights to represent the entire population of South Africa. ${ }^{37}$ During the 2002 survey, information on cigarettes 
was grouped with other items: 'Please indicate for each of the following items, on average, the NUMBER that you PERSONALLY SMOKE, DRINK OR USE PER DAY.' The question was simplified in the 2003-2011 surveys to: 'How many cigarettes did you personally smoke YESTERDAY?' From 2012, the survey did not ask respondents about smoking intensity. During the 2010-2011 surveys, an additional question was asked: 'Please indicate which ONE of the following statements applies to you: (1) I have never smoked, (2) I used to smoke but I stopped smoking, (3) I stopped smoking, but have started again, (4) I smoke, but intend stopping in the near future, or (5) I smoke and have no intention of quitting.' This question was also asked in the 2012-2014 surveys. Although AMPS 2005-2009 include questions on cigarette brands, we do not use this information.

From 2002 to 2008, AMPS included respondents aged 16 years and older, while 15 -year-olds were added in subsequent years.

Although we also have AMPS data for 2012-2014, the AMPS questionnaire in these years did not ask about the number of cigarettes smoked, which is an important variable for the gap analysis. The estimates from 2012 onwards are based on two assumptions. First, to calculate the annual self-reported consumption, we assume the average daily number of cigarettes smoked from 2012 to 2014 remains at the 2011 level of 9.1 cigarettes per smoker, based on NIDS data. According to NIDS, the smoking intensity in 2012 was 8.28 cigarettes per day $(95 \%$ CI 8.05 to 8.50 ), which decreased to 8.25 cigarettes per day in 2015 (95\% CI 8.03 to 8.47 ).

Since the difference between 2012 and 2015 is not statistically significant in the NIDS data, we use the 2011 AMPS estimate of cigarettes smoked per day for 2012-2014. In addition, there has not been major legislative or tax-related changes in the post-2011 period, so the assumption that the average daily number of cigarettes consumed by smokers is unlikely to have changed much seems reasonable. Although the average number of cigarettes smoked per day remained fairly constant between 2002 and 2011 (mean=8.9, $\mathrm{SD}=0.2$, minimum $=8.7$, maximum $=9.2$ ), there seems to be an increase in smoking intensity in the past few years (table 1).

Second, from 2015 to 2017, where we do not have AMPS data (2015) or where AMPS has been discontinued (2016 and 2017), we assume that the number of cigarettes consumed annually remains at the 2014 level. While this assumption may seem somewhat heroic at the outset, we believe that it is not unrealistic. As with the assumption for average smoking trends (mentioned in the previous paragraph), there have been no significant tobacco control interventions between 2015 and 2017. Furthermore, NIDS data for 2015 and 2017 follows a similar trend.

NIDS is a panel survey of the South African population that focuses, among other things, on income, consumption, expenditure, fertility and mortality, health, and education. A stratified, two-stage cluster sample design was used to sample the households included in the base wave. ${ }^{38}$ The adult questionnaire, in which the smoking questions were asked, is completed by respondents aged 15 years and older. Respondents were asked five smoking-related questions, two of which are used in this analysis: 'Do you smoke cigarettes?' and 'On average, how many cigarettes per day did you/ do you smoke?' Weights are applied to scale up the estimates to represent the population. To correct for attrition between waves, new sample members are included in subsequent waves to 2008. Although NIDS is a panel survey, we treat each data set as a cross section. All NIDS questionnaires ask respondents about smoking intensity.
To create confidence intervals around annual self-reported cigarette consumption, we bootstrap the point estimate of the product of smoking prevalence and smoking intensity using 1000 repetitions. ${ }^{39}$ Where we do not have smoking intensity data (2012-2014), we only bootstrap the number of smokers, assuming smoking intensity is 9.1 cigarettes per day for each smoker.

In order to standardise population estimates across the two surveys and to smooth the data, we used population estimates from the United Nations (UN; age 15+). Since both surveys consistently report lower population estimates than the UN data, we use an uplift factor to inflate the weights. For AMPS the uplift factor from 2002 to 2014 averaged 1.1 ( $S D=0.04$, minimum $=1.03$, maximum $=1.15$ ), while for NIDS it averaged $1.17(\mathrm{SD}=0.04$, minimum $=1.15$, maximum $=1.24)$.

For the 3 years for which AMPS and NIDS data overlap (2008, 2010 and 2012) the average difference in prevalence estimates is 2 percentage points. Differences in prevalence estimates from different surveys are not uncommon: a 2017 paper comparing smoking prevalence estimates from two Canadian national surveys finds an average difference of 3.5 percentage points for the years $2001-2013 .{ }^{40}$ The variance in prevalence estimates could reflect differences in the way the cigarette consumption questions are worded, different sample methodologies and different questionnaire content. AMPS is a product-use survey that asks about specific brands used (groceries, cleaning products, cosmetics, medication and alcohol, among other things), while NIDS asks about income, consumption, expenditure, fertility and mortality, health, education and outlook about the future. It seems likely that respondents to the AMPS questionnaire might answer more 'appropriately' than respondents to the NIDS questionnaire, given that AMPS is purely focused on consumption. This results in less under-reporting in AMPS than in NIDS.

To account for this under-reporting, we use under-reporting estimates of $5 \%$ and $10 \%$ for AMPS, while for NIDS we use $15 \%$ and $20 \%$. This ensures that the volume of illicit trade would not be less than zero since negative illicit trade is nonsensical. The calculation for $5 \%$ under-reporting is $\mathrm{x} / 0.95$, where $\mathrm{x}$ is self-reported consumption.

Excise revenue from domestic cigarettes was obtained from annual national budgets compiled by the National Treasury of South Africa. ${ }^{41}$ Excise tax revenue captured as 'Cigarettes and cigarette tobacco' essentially represents excise tax collections from domestic cigarette sales since the market share of 'cigarette tobacco' is marginal.

For each financial year (April to March of the following year) we obtained the number of cigarettes sold by dividing the excise revenue by the excise tax per cigarette, which is levied as a specific tax in South Africa. The data were converted to the calendar year by using appropriate weightings (ie, 9 months of one financial year and 3 months of the following financial year). Excise tax received from imported cigarettes is captured as part of 'Miscellaneous customs and excise receipts'. Since the category includes other products, it is not possible to establish the amount received from cigarettes. Instead, we obtained the kilograms of imported cigarettes from the Department of Trade and Industry's website. ${ }^{42}$ We use a conversion rate of $1 \mathrm{~kg}=1000$ cigarettes. ${ }^{43}$

Since there is substantial variation in the data (in particular, there are three spikes in the data, one of which does not correspond with an increase in revenue received), we use the median number of imports from 2002 to 2015 (1.9 billion cigarettes a year). We left the numbers unchanged for 2016 (3.0 billion) and 
Table 1 Summary statistics

\begin{tabular}{|c|c|c|c|c|c|c|c|}
\hline Survey & Year & $\begin{array}{l}\text { Total adult population } \\
\text { (million) }\end{array}$ & $\begin{array}{l}\text { Smoking prevalence } \\
(\%)\end{array}$ & Smokers, n (million) & $\begin{array}{l}\text { Average daily } \\
\text { intensity }\end{array}$ & $\begin{array}{l}\text { Annual self-reported } \\
\text { consumption (billion) }\end{array}$ & $\begin{array}{l}\text { (National Treasury and } \\
\text { Department of Trade } \\
\text { and Industry) (billion) }\end{array}$ \\
\hline \multirow[t]{21}{*}{ AMPS } & 2002 & 31.58 & 25.15 & 7.94 & 9.07 & 26.31 & 26.13 \\
\hline & 2003 & 32.19 & 23.74 & 7.64 & 9.16 & 25.56 & 26.02 \\
\hline & & & (23.05 to 24.44 ) & (7.42 to 7.87 ) & (8.94 to 9.39 ) & (24.48 to 26.64 ) & \\
\hline & 2004 & 32.79 & 24.45 & 8.02 & 8.89 & 26.01 & 25.64 \\
\hline & 2005 & 33.36 & 24.29 & 8.10 & 8.82 & 26.09 & 25.70 \\
\hline & & & (23.57 to 25.02 ) & (7.86 to 8.35 ) & (8.60 to 9.04 ) & (24.93 to 27.25 ) & \\
\hline & 2006 & 33.87 & 24.57 & 8.32 & 8.73 & 26.52 & 26.15 \\
\hline & & & (23.85 to 25.30 ) & (8.08 to 8.57 ) & (8.51 to 8.94 ) & (25.30 to 27.73 ) & \\
\hline & 2007 & 34.36 & 25.25 & 8.68 & 8.71 & 27.58 & 26.65 \\
\hline & & & (24.52 to 25.97 ) & (8.43 to 8.93 ) & (8.50 to 8.92 ) & (26.30 to 28.87 ) & \\
\hline & & & (22.61 to 23.99 ) & (7.99 to 8.48 ) & (8.55 to 9.00 ) & (25.02 to 27.74 ) & \\
\hline & 2010 & 35.89 & 19.77 & 7.09 & 9.21 & 23.85 & 23.56 \\
\hline & & & (19.11 to 20.42 ) & (6.86 to 7.33 ) & (8.98 to 9.45 ) & (22.65 to 25.06 ) & \\
\hline & 2011 & 36.48 & 20.17 & 7.36 & 9.10 & 24.41 & 22.78 \\
\hline & & & (19.51 to 20.82 ) & (7.12 to 7.60 ) & (8.88 to 9.32 ) & (23.13 to 25.70 ) & \\
\hline & 2012 & 37.11 & 21.08 & 7.82 & 9.10 & 25.98 & 23.06 \\
\hline & & & (20.41 to 21.75 ) & (7.57 to 8.07 ) & & (24.75 to 27.21 ) & \\
\hline & 2013 & 37.76 & 20.97 & 7.92 & 9.10 & 26.30 & 22.18 \\
\hline & & & (20.30 to 21.63 ) & (7.67 to 8.17 ) & & (25.11 to 27.49 ) & \\
\hline & 2014 & 38.42 & 20.78 & 7.98 & 9.10 & 26.51 & 23.17 \\
\hline & & & (20.12 to 21.43 ) & (7.73 to 8.23 ) & & (25.29 to 27.73 ) & \\
\hline \multirow{6}{*}{ NIDS } & 2012 & 37.11 & 19.65 & 7.29 & 8.28 & 22.02 & 23.06 \\
\hline & & & (18.90 to 20.39$)$ & (7.01 to 7.57 ) & (7.98 to 8.57 ) & (19.29 to 24.76$)$ & \\
\hline & 2015 & 39.07 & 20.34 & 7.95 & 8.25 & 23.93 & 23.02 \\
\hline & & & (19.65 to 21.03 ) & (7.68 to 8.22 ) & (7.96 to 8.54 ) & (21.03 to 26.83 ) & \\
\hline & 2017 & 40.28 & 19.89 & 8.01 & 8.04 & 23.49 & 19.42 \\
\hline & & & (19.20 to 20.57 ) & (7.73 to 8.29 ) & (7.76 to 8.31 ) & (20.35 to 26.63 ) & \\
\hline
\end{tabular}

AMPS sample sizes vary between 20377 and 29458 respondents. NIDS sample sizes vary between 15556 and 22493 respondents. Numbers in brackets show $99 \%$ Cls. Numbers in italics are authors' own estimates: we assume that smoking intensity in 2012-2014 remains at the 2011 estimate of 9.1 cigarettes per day and that annual selfreported consumption in 2015-2017 remains at the 2014 level of 26.51 billion cigarettes.

Source: All Media and Products Survey (AMPS, 2002-2014); ${ }^{3031}$ National Income Dynamics Study (NIDS, 2008, 2010, 2012, 2015, 2017); ${ }^{32-36}$ United Nations; ${ }^{44}$ National Treasury; ${ }^{41}$ and Department of Trade and Industry. ${ }^{42}$

2017 (3.4 billion) as SARS informed us that imports increased significantly in these 2 years.

Results are computed using Stata V.14.0 and Microsoft Excel.

\section{RESULTS}

Table 1 presents the summary statistics from AMPS, NIDS, the UN, National Treasury and the Department of Trade and Industry. Column 3 shows the total population of South Africa retrieved from the UN database (age $15+) .{ }^{44}$ Between 2002 and 2010, smoking prevalence, as reported in AMPS, decreased from
$25.15 \%$ (99\% CI 24.50 to 25.80 ) to $19.77 \%$ (99\% CI 19.11 to 20.42), followed by an increase to $20.78 \%$ (99\% CI 20.12 to 21.43 ) in 2014 (column 4). Smoking prevalence, as reported in NIDS, decreased between 2008 and 2010, and then increased in 2012 and 2015, followed by a slight decrease in 2017. Overall, smoking prevalence based on NIDS data decreased slightly from $21.12 \%$ (99\% CI 20.28 to 21.97 ) in 2008 to $19.89 \%$ (99\% CI 19.20 to 20.57 ) in 2017.

Smoking intensity (ie, the average number of cigarettes smoked per smoker per day) is shown in column 6. AMPS 


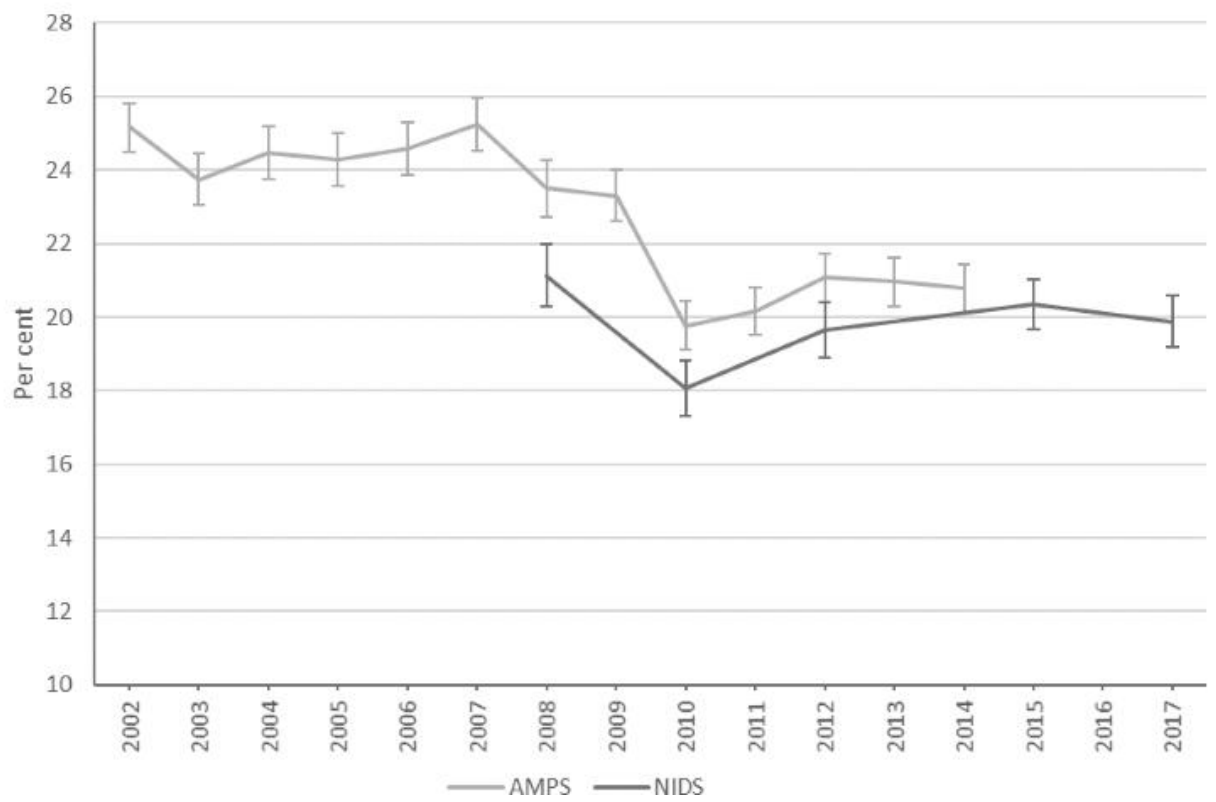

Figure 1 Smoking prevalence: All Media and Products Survey (AMPS, 2002-2014) and National Income Dynamics Study (NIDS, 2008-2017). Error bars indicate $99 \% \mathrm{Cls}$.

indicates a slight decrease in smoking intensity between 2003 and 2008, followed by a slight upward trend subsequently. Based on AMPS data, smoking intensity averaged 8.9 cigarettes a day in the 2002-2011 period, while it averaged 8.3 cigarettes a day in the NIDS surveys (2008-2017). While AMPS reports higher levels of consumption than NIDS, both surveys report similar trends (column 7). For example, between 2008 and 2010, AMPS reports a decrease of $7.8 \%$ in consumption while NIDS reports an $8.9 \%$ decrease.

Smoking prevalence reported by NIDS is consistently and significantly lower than AMPS estimates for overlapping years (figure 1). However, the trends produced by both surveys are consistent over time.

The gap method of estimating the size of the illicit market focuses on the difference between tax-paid consumption and survey-based consumption. Tax-paid consumption (as recorded by National Treasury and the Department of Trade and Industry) and surveybased consumption, as recorded by AMPS (figure 2) and NIDS (figure 3), were set equal to 100 in the initial year (2002 for AMPS and 2008 for NIDS). Comparing trends in these two measures of consumption provides information on changes in illicit trade over time.

Between 2002 and 2009, illicit trade remained at levels close to that of the base year. Levels of illicit trade began to change from 2009. Both figure 2 (AMPS data) and figure 3 (NIDS data) show that from 2010 tax-paid sales declined steeply, indicating an increase in illicit trade, which became statistically significant from 2011.

Illicit trade as a share of the total market is calculated as the gap (self-reported consumption less tax-paid consumption) divided by

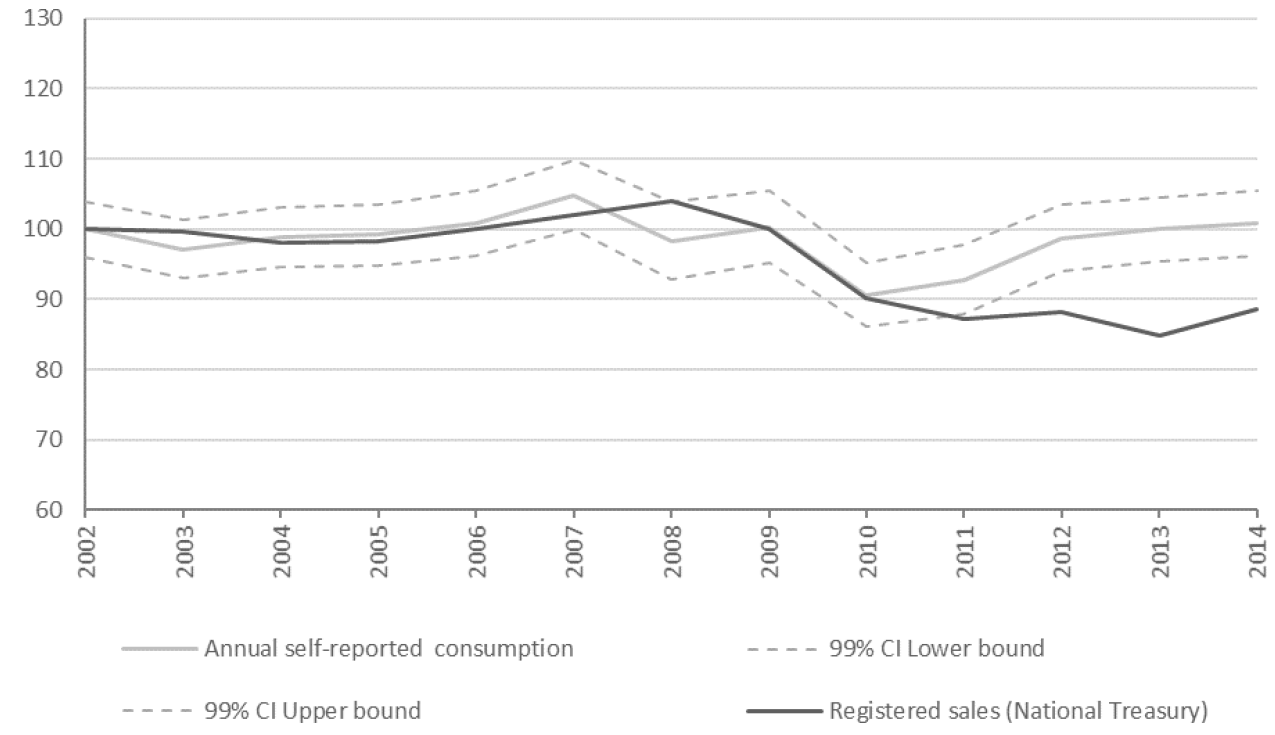

Figure 2 Annual survey-based consumption (All Media and Products Survey, AMPS) and tax-paid consumption (National Treasury and Department of Trade and Industry): 2002-2014 (2002=100). 


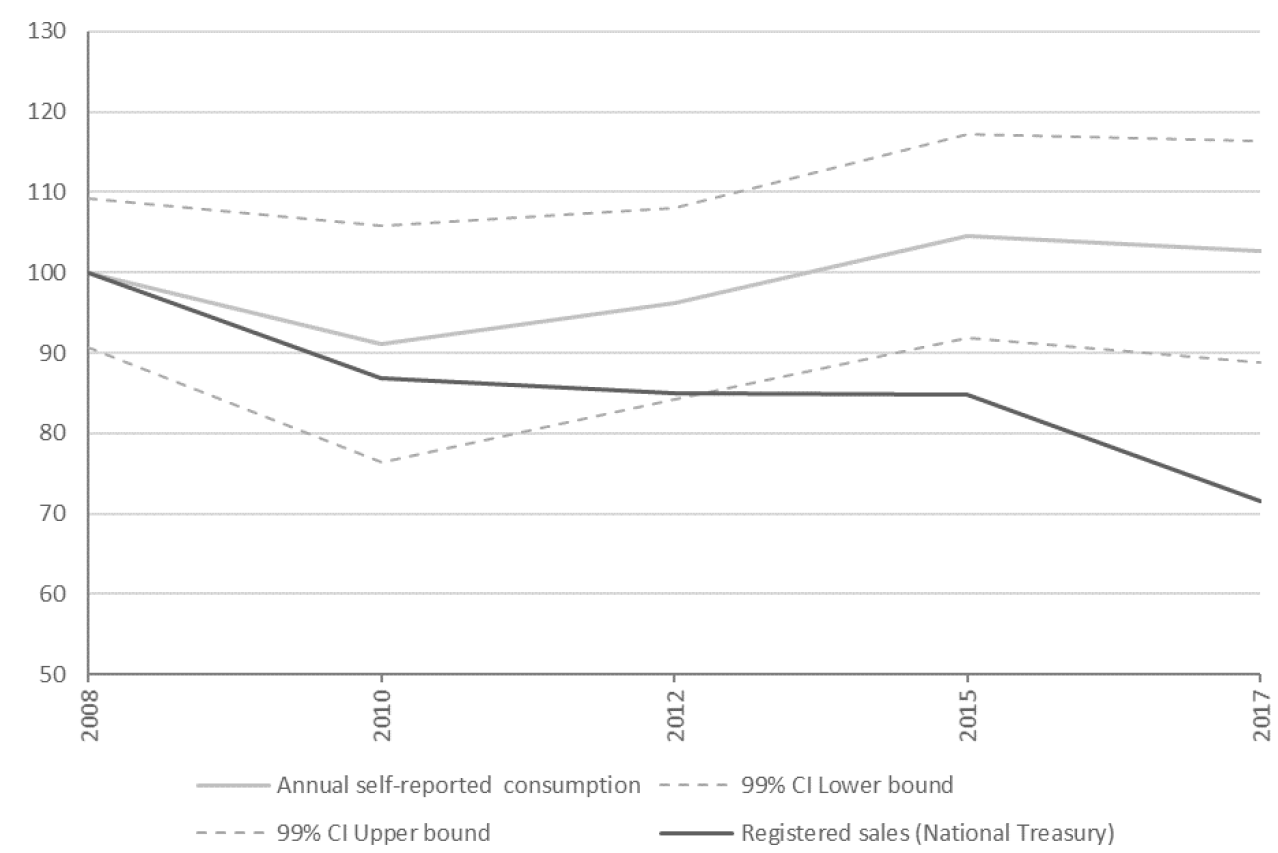

Figure 3 Annual survey-based consumption (National Income Dynamics Study, NIDS) and tax-paid consumption (National Treasury and Department of Trade and Industry): 2008-2017 (2008=100).

self-reported consumption (figures 4 and 5). We apply a 3-year moving average to self-reported consumption estimates to smooth the data (2 years in 2002 and 2014 in AMPS and 2 years in 2008 and 2017 in NIDS). Assuming under-reporting of 5\% in the AMPS data, illicit trade hovered around 5\% from 2002 to 2009, followed by a sharp increase: from 2009 to 2017 , illicit trade increased from approximately $2 \%$ to $30 \%$. Both data sets show a steep increase in illicit trade between 2015 and 2017. In 2017, illicit trade using AMPS data is between 30\% (5\% under-reporting) and 34\% (10\% under-reporting), which is similar to NIDS: $30 \%$ (15\% under-reporting) and 35\% (20\% under-reporting).

\section{DISCUSSION}

Between 2002 and 2010, we estimate that the illicit trade of cigarettes in South Africa accounted for less than 10\% of the total market, assuming 5\% under-reporting of survey data. At this time, SARS investigated manufacturers suspected of evading excise and VAT payments. From 2005 to about 2009, SARS enforcement units shut down a number of manufacturers and traders involved in fraud, smuggling and illicit manufacturing, including Mastermind Tobacco and Masters International Tobacco Manufacturing. ${ }^{45} 46$ The closing of these manufacturers, together with the very high

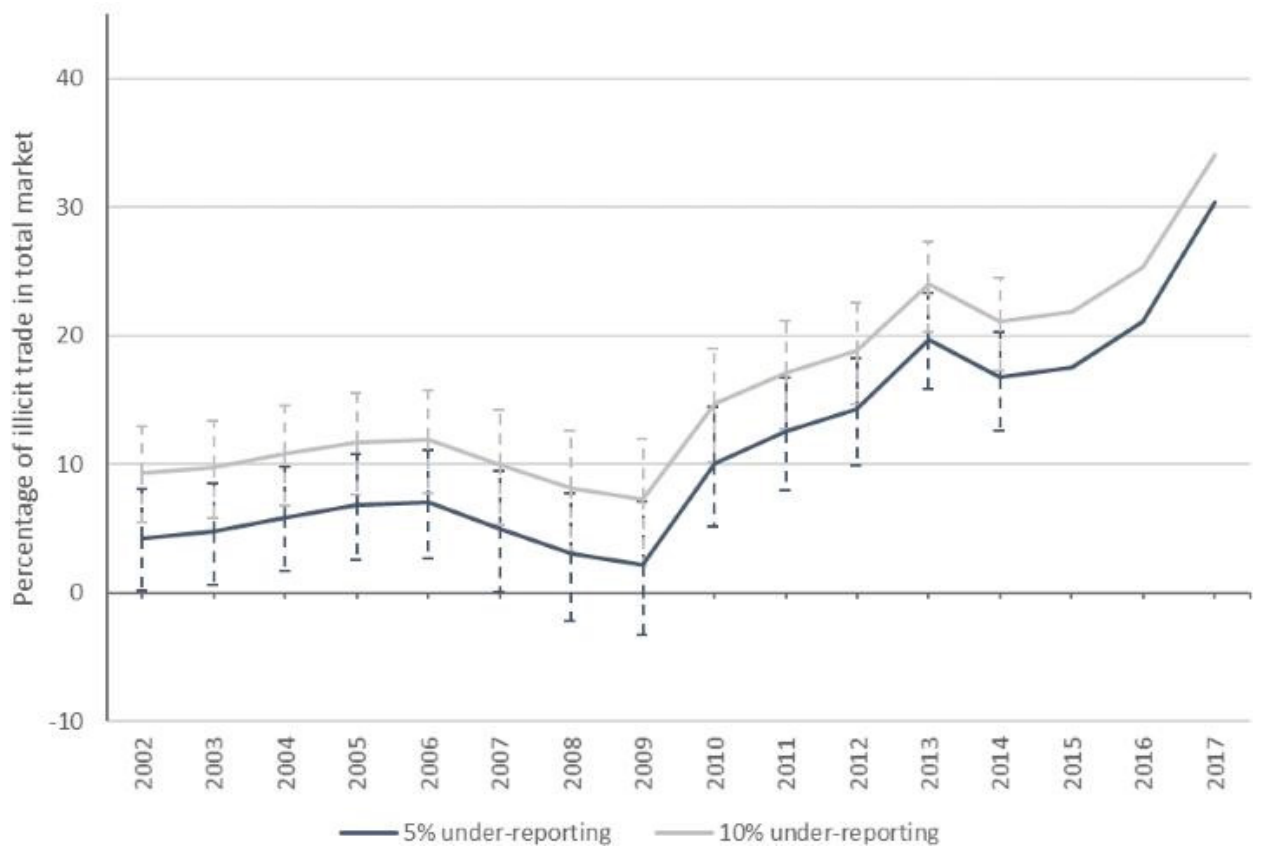

Figure 4 Share of illicit cigarettes in the total market in South Africa using All Media and Products Survey (AMPS) data: 2002-2017. Dashed error bars indicate $99 \%$ Cls. 


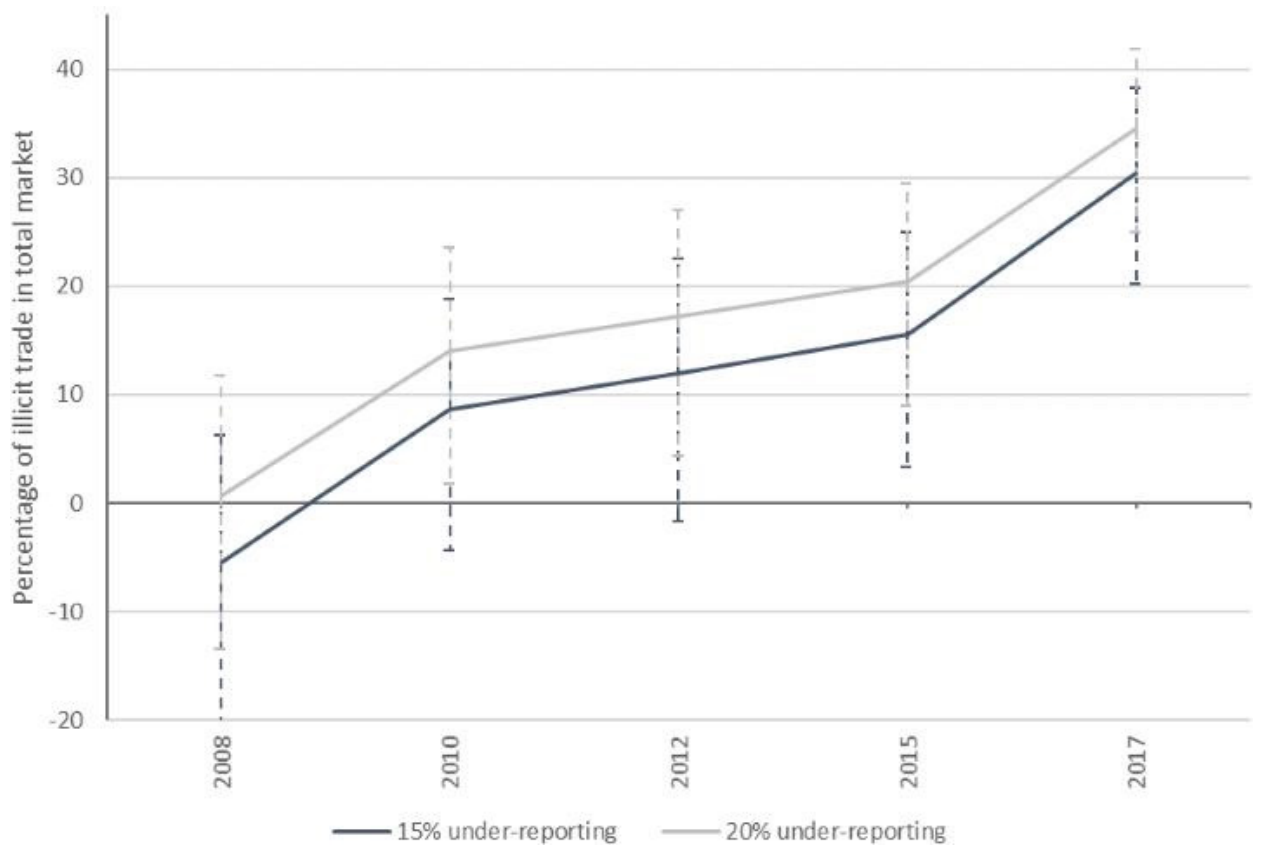

Figure 5 Share of illicit cigarettes in the total market in South Africa using National Income Dynamics Study (NIDS) data: 2008-2017. Dashed error bars indicate $99 \% \mathrm{Cls}$.

net-of-tax prices earned by the incumbent firms, created an incentive for new entrants to enter the market. Anecdotal evidence from ex-employees at SARS suggests that these new entrants accounted for a large proportion of the increase in illicit trade from around 2009 onwards.

In 2013, SARS established Project Honey Badger to investigate cigarette illicit trade. ${ }^{47}$ These investigations sought to identify cigarette manufacturers who were not paying excise taxes and VAT on the cigarettes they produced. In July 2014, SARS announced that investigations under Project Honey Badger had resulted in a $25 \%$ increase in excise and VAT payments, ${ }^{48}$ which explains the decrease in illicit trade in 2014 and 2015. Since 2015, these gains have been lost.

Following Tom Moyane's appointment as SARS Commissioner in September 2014, SARS has been purged of many senior executives, which included personnel who worked on tax and customs enforcement and investigations. ${ }^{6} 49$ Five specialised units were disbanded, all of which were investigating the illegal cigarette trade under Project Honey Badger. ${ }^{49}$

We attribute the substantial increase in the illicit cigarette trade since 2009 and especially since 2015 primarily to the diminished capability of SARS in recent years to perform its vital functions. ${ }^{6}$

Providing estimates of the share of illicit trade allows a comparison with previous results. We conclude that our estimates compare reasonably well with Van Walbeek, ${ }^{8}$ with a correlation coefficient of $0.8(p=0.020)$ for the nine overlapping years (2004-2012). There are only five overlapping years between this study and Blecher's paper (2003-2007). ${ }^{11}$ The correlation coefficient is insignificant.

According to the latest industry estimates ${ }^{13}$ the illicit trade market share accounted for $26.8 \%$ of the total market in June 2018. Our estimates are surprisingly similar to those of the industry: we estimate that illicit trade in 2017 is between 30\% and 35\%. Our 2017 estimates of illicit trade correspond well with another study on the South African market for illicit cigarettes. ${ }^{50}$ The authors use NIDS 2017, the first year NIDS asks respondents about cigarette prices, to estimate illicit trade by establishing a threshold price, which distinguishes tax-paid cigarettes from non-tax-paid cigarettes. They find that approximately $30 \%$ of cigarettes bought in 2017 evaded excise tax. ${ }^{50}$

Our estimates are subject to several limitations. First, the gap analysis method cannot distinguish between tax avoidance and tax evasion and cannot determine whether illicit cigarettes are counterfeit, contraband or illicit domestic production. TISA's study, ${ }^{13}$ previous investigative journalism ${ }^{51}$ and localised surveys of townships $^{52}$ point to illicit domestic manufacturing as the major source of the gap between consumption and sales. Second, gap analysis does not account for cigarette packs that, having paid excise tax, subsequently leave the country, for example, when people buy cigarettes in South Africa and consume them in neighbouring countries. However, we believe that this is a minor issue in South Africa since legal cigarettes in most neighbouring countries are priced similar to those in South Africa. If tax-paid cigarettes leave the country, the volume (and thus the share) of illicit trade would decrease as tax-paid sales would increase while survey-based consumption would remain unchanged. Third, self-reported estimates from surveys suffer because of under-reported consumption. ${ }^{25-27}$ To address under-reporting we included illicit trade estimates in which we scale up consumption. Fourth, the comparison between cigarette consumption and legal sales is complicated by the presence of roll-your-own cigarettes that might not be included in the official statistics, but are reported as cigarette consumption during the survey. Consequently, the comparison of survey-based consumption (that includes roll-your-own cigarettes) with tax-based sales would overestimate the level of tax evasion/avoidance. ${ }^{18}$ Since relatively few people in South Africa smoke roll-your-own cigarettes, this is unlikely to substantially affect our estimates.

\section{CONCLUSION}

It is clear that cigarette supply chain controls in South Africa need to be drastically improved. A track and trace system, for example, would ensure that all products manufactured in the country are accounted for. Tighter enforcement would further deter retailers from selling illicit cigarettes. 
While the illicit cigarette trade in South Africa is a serious problem, its presence should not be used to undermine tobacco control policy, because the underlying cause is weak tax administration, not the tax level. In fact, the rapid increase in the size of the illicit market occurred in a period when the real excise tax on cigarettes remained largely unchanged. In contrast, there is no evidence that the illicit market grew when the excise tax was growing rapidly (1995-2009). South Africa should ratify the Framework Convention on Tobacco Control's Protocol to Eliminate Illicit Trade in Tobacco Products and join the existing 52 parties. ${ }^{53}$ Becoming a Party to the Protocol would allow South Africa to draw on technical assistance and international collaboration in addressing its serious problem with illegal cigarettes.

\section{What this paper adds}

- We provide recent independent estimates of cigarette illicit trade in South Africa.

- We add to the growing body of literature that uses the methodology of gap analysis to measure illicit trade.

- Our results are nationally representative.

- We highlight the urgent action needed in South Africa to combat illicit trade.

Contributors NV and HR carried out the literature review. NV carried out data extraction, data analysis, and wrote the first draft. CVW assisted with the data analysis. All authors revised the manuscript and approved the final manuscript.

Funding This paper was funded by the Bill and Melinda Gates Foundation (through the African Capacity Building Foundation) (IRMA 20177).

\section{Competing interests None declared.}

Patient consent for publication Not required.

Provenance and peer review Not commissioned; externally peer reviewed.

Data availability statement The All Media and Products Survey and the National Income and Dynamics Study are available on a portal managed by DataFirst at the University of Cape Town. The United Nations population data are available on their website. National Treasury and Department of Trade and Industry data are available on the Republic of South Africa's website.

Open access This is an open access article distributed in accordance with the Creative Commons Attribution 4.0 Unported (CC BY 4.0) license, which permits others to copy, redistribute, remix, transform and build upon this work for any purpose, provided the original work is properly cited, a link to the licence is given, and indication of whether changes were made. See: https://creativecommons.org/ licenses/by/4.0/.

\section{REFERENCES}

1. Linegar DJ, Van Walbeek C. The effect of excise tax increases on cigarette prices in South Africa. Tob Control 2018;27:65-71.

2. Republic of South Africa. National Treasury. Budget speech. Available: http://www. treasury.gov.za/documents/national\%20budget/2004/speech/Speech.pdf [Accessed 18 February 2019].

3. Economics of Tobacco Control Project. South Africa time series data for cigarettes: 1960 - 2017 [dataset]. Version 1.0. Cape Town: Economics of Tobacco Control Project [producer]. Cape Town: DataFirst [distributor], 2018.

4. Joossens L, Raw M. From cigarette smuggling to illicit tobacco trade. Tob Control 2012;21:230-4

5. Blecher E, Drope J. The rewards, risks and challenges of regional tobacco tax harmonisation. Tob Control 2014;23:e7-11.

6. Kahn T. Tobacco excise revenue plunge shows SARS collection up in smoke. Business Day, 2018. Available: https://web.archive.org/save/https://www.businesslive.co.za/bd/ national/2018-05-29-tobacco-excise-revenue-plunge-shows-sars-collection-up-insmoke/ [Accessed 10 Aug 2018].

7. Tobacco Institute of Southern Africa. How serious is illicit trade. Available: https://web. archive.org/web/20180906131224/http://www.tobaccosa.co.za/illicit-trade/howserious-is-illicit-trade/ [Accessed 16 Oct 2018].

8. Van Walbeek C. Measuring changes in the illicit cigarette market using government revenue data: the example of South Africa. Tob Control 2014;23:e69-74.
9. Gallagher AWA, Evans-Reeves KA, Hatchard JL, et al. Tobacco industry data on illicit tobacco trade: a systematic review of existing assessments. Tob Control 2019;28:334-45.

10. Blecher E, Liber A, Ross $\mathrm{H}$, et al. Euromonitor data on the illicit Trade in cigarettes. Tob Control 2015;24:100-1.

11. Blecher E. A mountain or a molehill: is the illicit trade in cigarettes undermining tobacco control policy in South Africa? Trends Organ Crime 2010;13:299-315.

12. South African Revenue Service. Portfolio Committee on Trade \& Industry, 2014. Available: https://web.archive.org/web/20181008144419/https://www.thedti.gov.za/ parliament/2014/SARS_Presentation.pdf [Accessed 15 Oct 2018].

13. Ipsos. National tobacco market survey, 2018. Available: https://web.archive.org/web/ 20181016150805/http://www.tobaccosa.co.za/wp-content/uploads/IPSOS-2018National-Tobacco-Market-Study-Executive-Summary-1.pdf [Accessed 16 Oct 2018].

14. Van Rensburg D. The rot runs deep in the tobacco sector, 2018. Available: https://web. archive.org/save/https://www.fin24.com/Economy/South-Africa/the-rot-runs-deep-inthe-tobacco-sector-20180708-2 [Accessed 15 Oct 2018].

15. Tobacco Institute of Southern Africa. Our directors. Available: https://web.archive.org/ web/20180906123919/http://www.tobaccosa.co.za/about/our-directors/ [Accessed 15 Oct 2018].

16. Gilmore AB, Fooks G, Drope J, et al. Exposing and addressing tobacco industry conduct in low-income and middle-income countries. The Lancet 2015;385:1029-43.

17. Euromonitor International. Cigarettes in South Africa, 2017. Available: http://www. euromonitor.com/cigarettes-in-south-africa/report [Accessed 15 Oct 2018].

18. Ross H. Understanding and measuring tax avoidance and evasion: a methodological guide. Prepared for the Economics of Tobacco Control Project, School of Economics, University of Cape Town and Tobacconomics, Health Policy Center, Institute for Health Research and Policy, University of Illinois at Chicago, 2015. Available: http://www.tobaccoecon.uct.ac.za/etcp/publications/reports [Accessed 15 Oct 2018].

19. Her Majesty's Revenue and Customs. Measuring tax gaps 2018 edition: methodological annex, 2018. Available: https://www.gov.uk/government/statistics/ measuring-tax-gaps [Accessed 29 Jan 2019].

20. Paraje G. Illicit cigarette trade in five South American countries: a gap analysis for Argentina, Brazil, Chile, Colombia, and Peru. Nicotine Tob Res 2018;3.

21. Physicians for a Smoke-Free Canada. The Canadian tobacco market place. Estimating the volume of contraband sales of tobacco in Canada: 2006-2011. Ottawa: Physicians for a Smoke-Free Canada, 2013. (Updated and Revised—April 2011).

22. Guindon GE, Burkhalter R, Brown KS. Levels and trends in cigarette contraband in Canada. Tob Control 2017:26:518-25.

23. Stehr M. Cigarette tax avoidance and evasion.J Health Econ 2005;24:277-97.

24. Nguyen MT, Denniston R, Nguyen HTT, et al. The empirical analysis of cigarette tax avoidance and illicit trade in Vietnam, 1998-2010. PLOS ONE 2014;9:e87272.

25. Roth MA, Aitsi-Selmi A, Wardle $H$, et al. Under-reporting of tobacco use among Bangladeshi women in England. J Public Health 2009;31:326-34.

26. Pérez-Stable EJ, Marín BV, Marín G, et al. Apparent underreporting of cigarette consumption among Mexican American smokers. Am J Public Health 1990;80:1057-61.

27. Dietz PM, Homa D, England LJ, et al. Estimates of nondisclosure of cigarette smoking among pregnant and nonpregnant women of reproductive age in the United States. Am J Epidemiol 2011;173:355-9.

28. Szklo A, Iglesias RM, Carvalho de Souza M, et al. Trends in illicit cigarette use in Brazil estimated from legal sales, 2012-2016. Am J Public Health 2018;108:265-9.

29. Iglesias RM, Szklo AS, Souza MCde, et al. Estimating the size of illicit tobacco consumption in Brazil: findings from the global adult tobacco survey. Tob Control 2017:26:53-9.

30. South African Audience Research Foundation. All Media and Products Survey 2002 [dataset]. Version 1.1. Johannesburg: South African Audience Research Foundation [producer]. Cape Town: DataFirst [distributor], 2015.

31. South African Audience Research Foundation. All Media and Products Survey. In: Nielson. Cape Town: DataFirst, 2014.

32. Southern Africa Labour and Development Research Unit. National Income Dynamics Study 2010-2011, Wave 2 [dataset]. Version 3.1. Cape Town: Southern Africa Labour and Development Research Unit [producer], 2016. Cape Town: DataFirst [distributor], 2016.

33. Southern Africa Labour and Development Research Unit. National Income Dynamics Study 2012, Wave 3 [dataset]. Version 2.1. Cape Town: Southern Africa Labour and Development Research Unit [producer], 2016. Cape Town: DataFirst [distributor], 2016.

34. Southern Africa Labour and Development Research Unit. National Income Dynamics Study 2014 - 2015, Wave 4 [dataset]. Version 1.1. Cape Town: Southern Africa Labour and Development Research Unit [producer], 2016. Cape Town: DataFirst [distributor], Pretoria: Department of Planning Monitoring and Evaluation [commissioner], 2014.

35. Southern Africa Labour and Development Research Unit. National Income Dynamics Study 2017, Wave 5 [dataset]. Version 1.0.0 Pretoria: Department of Planning, Monitoring, and Evaluation [funding agency]. Cape Town: Southern Africa Labour and Development Research Unit [implementer], DataFirst [distributor], 2018.

36. Southern Africa Labour and Development Research Unit. National Income Dynamics Study 2008, Wave 1 [dataset]. Version 6.1. Cape Town: Southern Africa Labour and 
Development Research Unit [producer], 2016. Cape Town: DataFirst [distributor], 2016.

37. South Africa Market Audience Foundation. The evolution of AMPS, 2012. Available: www.saarf.co.za/amps/amps-evolution.asp

38. Leibbrandt M, Woolard I, De Villiers L. National Income Dynamic Study. Methodology: report on NIDS wave 1. Technical Paper 2009.

39. Cameron AC, Trivedi PK. Microeconometrics using Stata. rev. ED. College Station, TX: Stata Press, 2010

40. Gagné T. Estimation of smoking prevalence in Canada: implications of survey characteristics in the CCHS and CTUMS/CTADS. Can J Public Health 2017;108:e331-4.

41. Republic of South Africa. National Treasury. National budget. Available: https://web. archive.org/web/20181016103436/http://www.treasury.gov.za/documents/national\% 20budget/default.aspx [Accessed 16 Oct 2018].

42. Republic of South Africa: Department of Trade and Industry. Trade data, 2019. Available: http://tradestats.thedti.gov.za

43. Organisation for Economic Co-operation and Development. Health statistics 2018 : definitions, sources and methods. Tobacco consumption in grams per capita (age 15+), 2018. Available: http://stats.oecd.org/wbos/fileview2.aspx?IDFile=8e59b8358196-426e-9297-15bc1dab652c

44. United Nations Department of Economic and Social Affairs. Population division. World population prospects, 2017. Available: https://population.un.org/wpp/Download/ Standard/Population/ [Accessed 10 Oct 2018].

45. Sole S. Smokes, sex and the arms deal. Mail \& Guardian, 2018. Available: https://web. archive.org/save/https://mg.co.za/article/2008-10-28-smokes-sex-and-the [Accessed 22 Oct 2018].
46 Independent Online. Cigarette firm accused of defrauding taxman, 2005. Available: https://web.archive.org/web/20181029105107/https://www.iol.co.za/news/southafrica/cigarette-firm-accused-of-defrauding-taxman-245099 [Accessed 20 Jan 2019].

47. Groenewald Y. SA fails to stub out dodgy ciggies. Mail \& Guardian, 2018. Available: https://web.archive.org/web/20181030135423/https://mg.co.za/article/2018-06-1500-sa-fails-to-stub-out-dodgy-ciggies [Accessed 30 Jan 2019].

48. Serrao A. Sars target of tobacco industry backlash. Independent Online, 2014. Available: https://web.archive.org/save/https://www.iol.co.za/news/south-africa/ gauteng/sars-target-of-tobacco-industry-backlash-1728457 [Accessed 22 Oct 2018].

49 Huffington Post. SARS is a mess thanks to Tom Moyane. Here's how he did it, 2018. Available: https://www. huffingtonpost.co.za/2018/03/20/the-damage-tom-moyanewrought-on-sars_a_23390102/ [Accessed 15 Oct 2018].

50. Van der Zee K, Van Walbeek C, Magadla S. Institutional failure and the availability of Illicit/Cheap cigarettes in South Africa. Under review at Trends in Organized Crime.

51. Bailey C. Sars to clamp down on tobacco companies. Independent Online, 2013. Available: https://web.archive.org/web/20181012110517/https://www.iol.co.za/ business-report/companies/sars-to-clamp-down-on-tobacco-companies-1611521 [Accessed 22 Oct 2018].

52. Van der Zee K, Vellios N, Ross $\mathrm{H}$, et al. The prevalence of illicit cigarette consumption in 6 South African townships. Under review at Tobacco Control.

53. World Health Organization. Framework Convention on Tobacco Control. Protocol to eliminate illicit trade in tobacco products, 2013. Available: http://www.who.int/fctc/ protocol/illicit_trade/protocol-publication/en/ [Accessed 16 Oct 2018]. 